\title{
Strengthening tropical Pacific zonal sea surface temperature gradient consistent with rising greenhouse gases
}

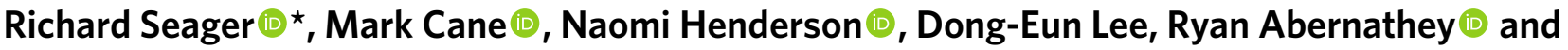 \\ Honghai Zhang ${ }^{(\mathbb{D}}$
}

\begin{abstract}
As exemplified by El Niño, the tropical Pacific Ocean strongly influences regional climates and their variability worldwide ${ }^{1-3}$. It also regulates the rate of global temperature rise in response to rising GHGs ${ }^{4}$. The tropical Pacific Ocean response to rising GHGs impacts all of the world's population. State-of-the-art climate models predict that rising GHGs reduce the west-toeast warm-to-cool sea surface temperature gradient across the equatorial Pacific ${ }^{5}$. In nature, however, the gradient has strengthened in recent decades as GHG concentrations have risen sharply ${ }^{5}$. This stark discrepancy between models and observations has troubled the climate research community for two decades. Here, by returning to the fundamental dynamics and thermodynamics of the tropical ocean-atmosphere system, and avoiding sources of model bias, we show that a parsimonious formulation of tropical Pacific dynamics yields a response that is consistent with observations and attributable to rising GHGs. We use the same dynamics to show that the erroneous warming in state-of-the-art models is a consequence of the cold bias of their equatorial cold tongues. The failure of state-of-the-art models to capture the correct response introduces critical error into their projections of climate change in the many regions sensitive to tropical Pacific sea surface temperatures.
\end{abstract}

Over the Pacific, easterly trade winds at the Equator drive water westward, creating high sea level and a deep thermocline (the sharp boundary between the warm upper and cool deep ocean) in the west, and low sea level and a shallow thermocline in the east. Because of the Earth's rotation, the trades drive waters away from the Equator, causing upwelling. Upwelling and a shallow thermocline create the equatorial cold tongue in the east and a sea surface temperature (SST) gradient towards the West Pacific warm pool (WPWP). The strength of the gradient varies over time. During warm, El Niño phases of the El Niño-Southern Oscillation, the SST gradient and easterly winds weaken, and deep convection in the atmosphere moves from the WPWP to the normally cooler central equatorial Pacific (CEP) and eastern equatorial Pacific (EEP). In a coupled atmosphere-ocean process, weakened easterlies reduce upwelling, causing warming, and the weaker SST gradient further weakens the easterlies, causing the Bjerknes feedback ${ }^{1}$. Wind-driven transient adjustment of the thermocline allows oscillation between El Niño and cold (La Niña) events on interannual and longer time scales. Changes in the SST gradient and location of deep convection are communicated by Kelvin and Rossby waves into global atmospheric circulation and climate anomalies ${ }^{3}$. During La Niña events, many tropical land masses are anomalously wet while drought impacts the extratropical Americas and East Africa ${ }^{2}$. El Niño impacts are approximately opposite. On decadal time scales, an overall stronger than normal SST gradient since 1998 has driven dry conditions in western North America ${ }^{7}$ and East Africa ${ }^{8}$, and temporarily reduced the rate of global warming in the atmosphere by enhancing the rate of ocean heat uptake ${ }^{4}$.

The SST gradient probably also responds to external forcing. Over the period of instrumental measurement of SST, amid nearuniversal warming, the CEP to EEP has either not warmed or cooled $^{5}$ (Fig. 1a,b,g). It has been argued that, in response to rising GHGs, upwelling and the shallow thermocline allow some of the added heat to be diverged away from the cold tongue such that it warms less than the WPWP. The Bjerknes feedback amplifies this forced response, creating stronger trades and a stronger zonal SST gradient $^{9,10}$. In contrast, the Climate Model Intercomparison Project (CMIP; most recently Phase 5 (CMIP5)) models tend to simulate broad warming over the past century, with enhanced warming in the cold tongue ${ }^{5}$. This response has been explained in terms of exponential dependence of saturation vapour pressure on temperature, necessitating a larger SST change to balance enhanced downward longwave radiation in the cooler east than warmer west ${ }^{11}$, weakening of the Walker Circulation ${ }^{12}$, and limitation of SST increase by cloud feedbacks over the West Pacific ${ }^{13}$. In Fig. 1g, the cold tongue trends over the entire period analysed here (1958-2017) from 88 CMIP5 model runs and 35 runs from the National Center for Atmospheric Research (NCAR) Large Ensemble (LENS) are compared with four observational SST products: two show no overlap with the models, while the other two lie in the low side of the model distribution. If the observed lack of cold tongue warming is a result of natural variability, it would be expected that many of these 123 simulations, which sample model natural variability well, would produce it. Furthermore, it would be expected that the difference between modelled and observed cold tongue SST change would depend on the choice of start and end dates of trends. Instead, a decade of 60-year trends shows a consistent and widening observations-model discrepancy (Fig. 1g). One explanation is that state-ofthe-art climate models have biases in simulation of the cold tongue, Intertropical Convergence Zone, and thermocline and zonal asymmetries of the tropical Pacific ${ }^{14}$ and, hence, how these respond to rising GHGs. This SST trend discrepancy has implications for climate projections worldwide.

Previous studies have used statistical methods to examine discrepancies between CMIP5 and observed tropical Pacific SST trends, over a shorter period more influenced by changes in the phase of natural decadal variability ${ }^{15}$. Here, we examine a longer 

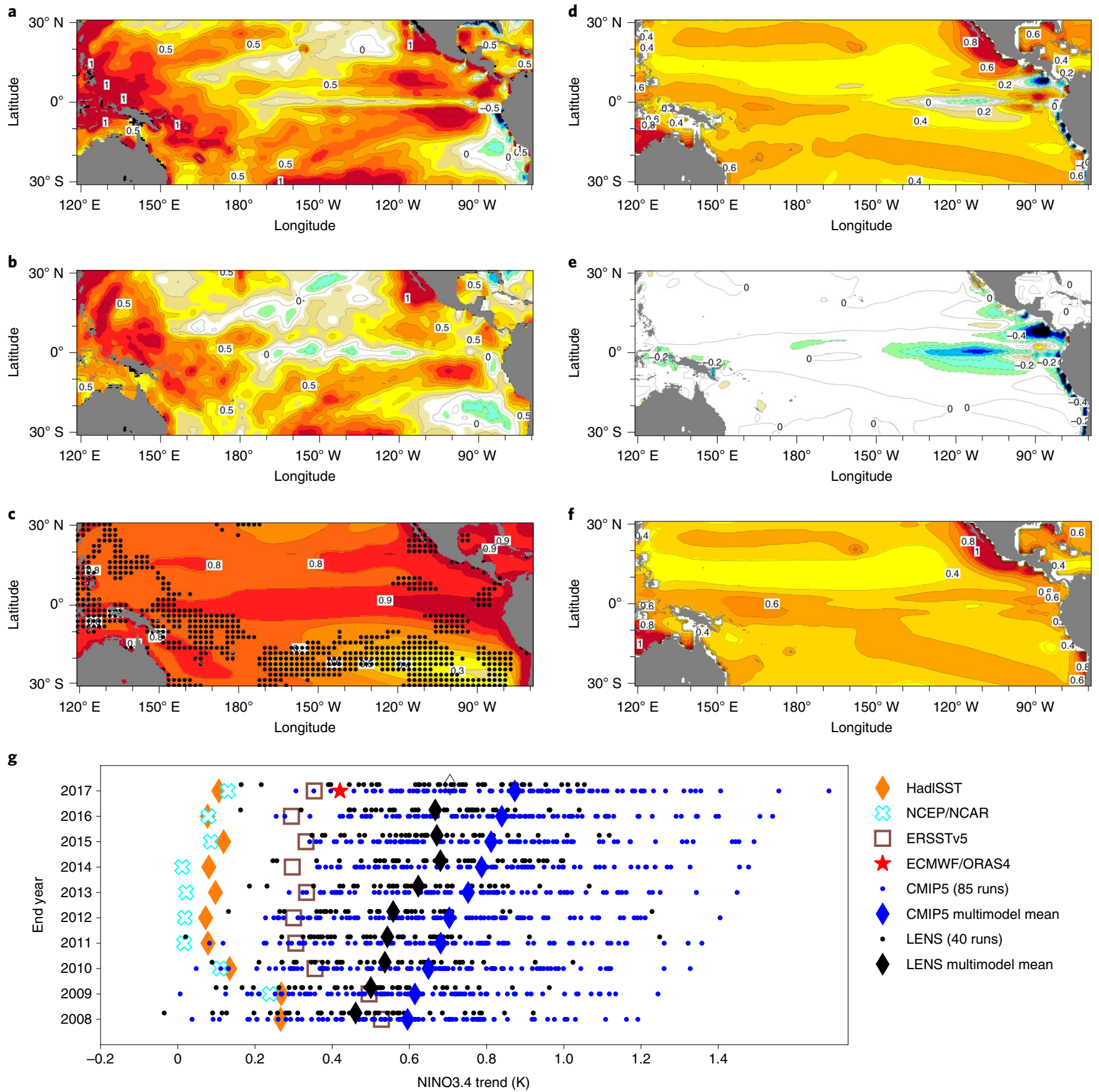

Fig. 1 | SST trends over 1958-2017. a-c, Observed changes in SST (K) according to ECMWF/ORAS4 reanalysis (a), HadISST analysis (b) and the multimodel mean of 40 historical and RCP8.5 CMIP5 models (c), with stippling in c showing where the median trend of the CMIP5 models is between the maximum and minimum trends of the four SST analyses. d-f, Simulations from the ocean model forced by rising $\mathrm{CO}_{2}$ and observed winds (d), observed winds only, with fixed $\mathrm{CO}_{2}(\mathbf{e})$ and rising $\mathrm{CO}_{2}$ with fixed winds (f). The observed SST trend of no warming in the cold tongue amid widespread warming can be reproduced by the ocean model as a combined thermodynamic and dynamic response to $\mathrm{CO}_{2}$ and wind stress change. $\mathbf{g}$, Distribution of 60 -year trends in the NINO3.4 SST index (SST averaged over $5^{\circ} \mathrm{S}-5^{\circ} \mathrm{N}$ and $170^{\circ} \mathrm{W}-120^{\circ} \mathrm{W}$ ) for end dates from 2008-2017 for 88 individual CMIP5 model runs and 35 NCAR LENS runs, together with observational estimates from ECMWF, HadISST, National Centers for Environmental Prediction (NCEP)/NCAR and ERSSTv5 SST analyses. The observed SST trends ending in the current decade are either colder than, or at the very limit of, the range of trends in individual CMIP5 and LENS model runs.

period and apply fundamental dynamic theory to the problem in three steps. First, with an ocean model with minimal but adequate structure, we show that the observed SST trend is consistent with an ocean response to the observed wind stress change plus increasing $\mathrm{CO}_{2}$. Second, using a basic atmosphere model, we show that the observed wind stress change is consistent with an atmosphere response to the SST change. Third, we couple the models and show that observed changes in SST and winds are consistent with a coupled response to rising $\mathrm{CO}_{2}$. To avoid potential sources of bias, and setting them apart from standard CMIP models, our models take 

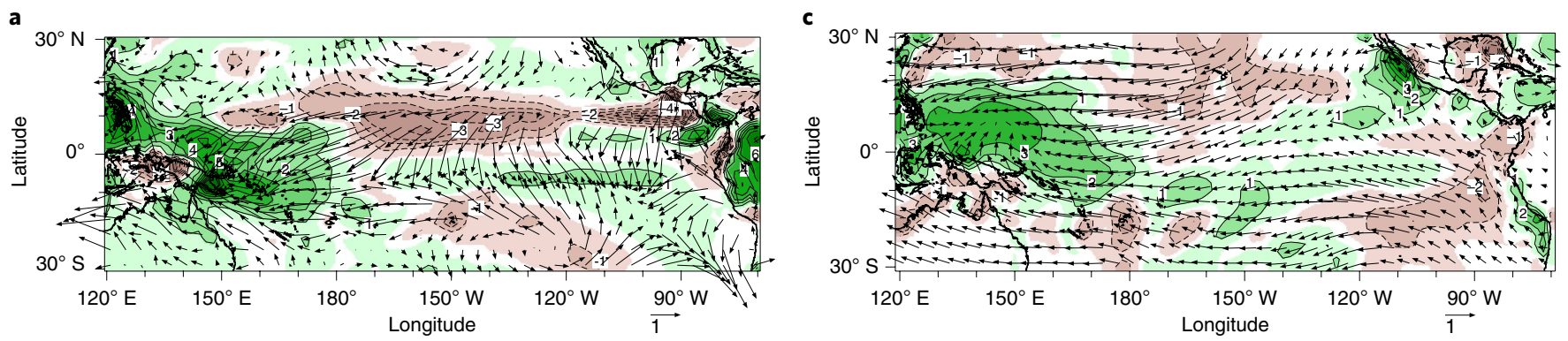

b

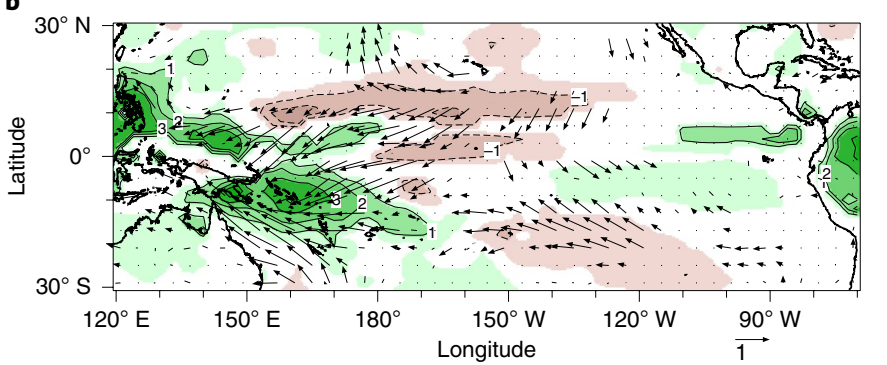

d
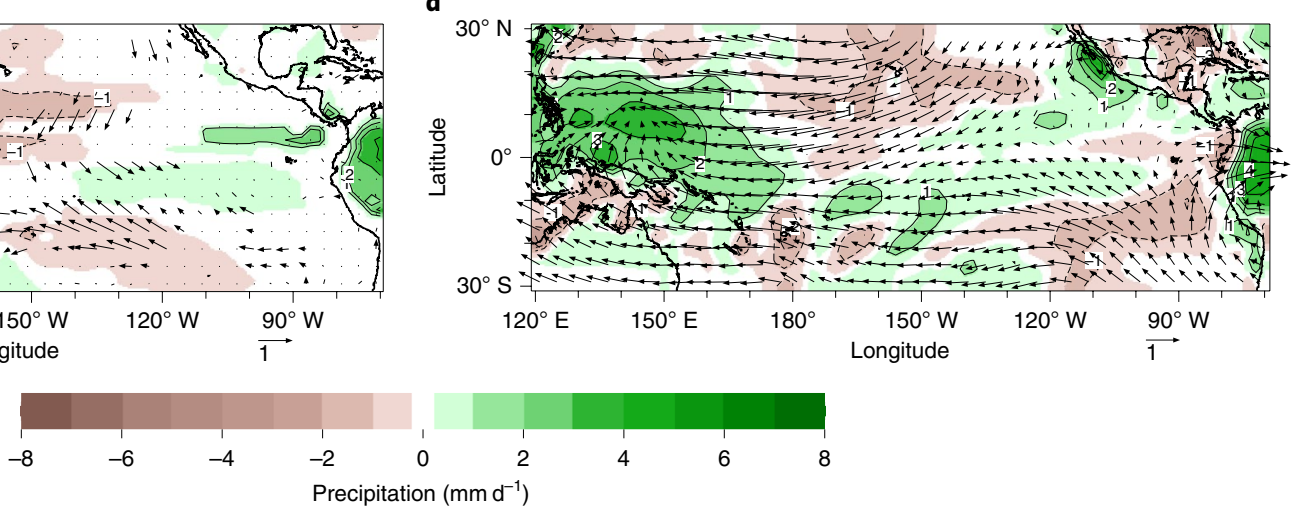

Fig. 2 | Atmosphere trends over 1958-2017. a-d, Trends in surface winds (vectors; the arrow in the bottom right of each panel is a scale bar representing $1 \mathrm{~m} \mathrm{~s}^{-1}$ ) and precipitation (colours/contours and numerical labels; see also scale bar), based on ECMWF reanalysis over 1958-2017 (a), means from ECMWF, Twentieth Century Reanalysis and Japan Meteorological Agency reanalysis over 1958-2013 (when the Japan Meteorological Agency reanalysis ended), but only where all three agree on the direction of wind trend in the same quadrant and the precipitation trend is of the same sign (b), simulations by the atmosphere model forced by the observed ECMWF ORAS4 SST trend only (c) and simulations by the atmosphere model forced by trends in ECMWF SST and heating over land (d).
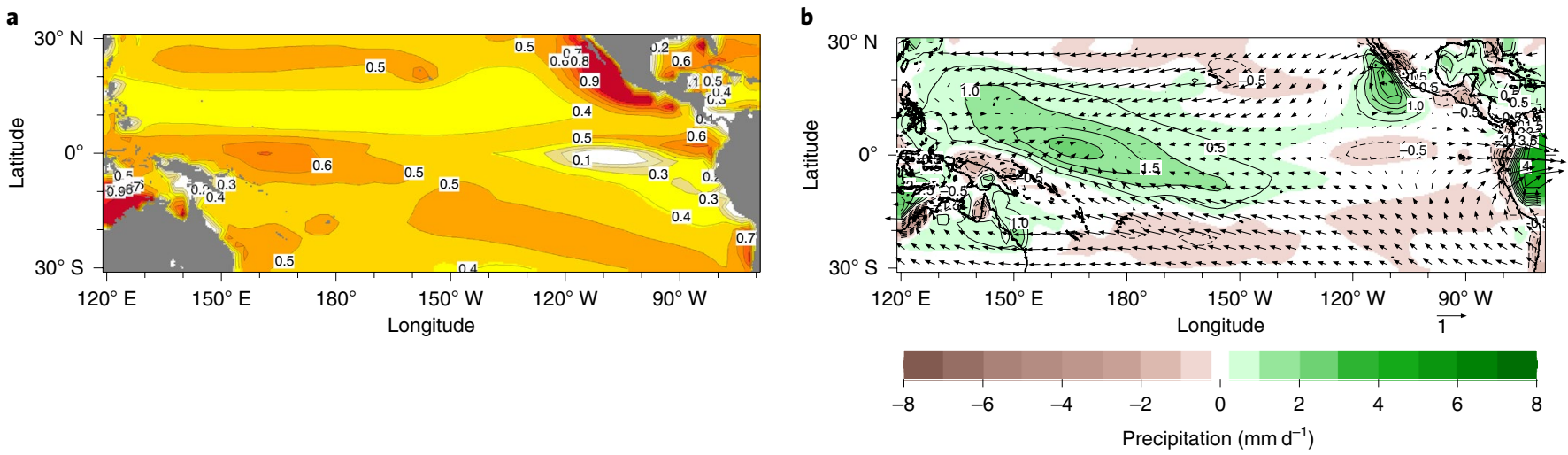

Fig. 3 | Results from the coupled atmosphere and ocean model simulations. $\mathbf{a}, \mathbf{b}$, SST change (a; colours/contours and numerical labels (in K)) and precipitation change ( $\mathbf{b}$; colours/contours and numerical labels (in $\mathrm{mm} \mathrm{d}^{-1}$ ) for the model forced only by the $\mathrm{CO}_{2}$ change over 1958-2017 and the precipitation trend over the Amazon. The vectors in $\mathbf{b}$ represent change in surface wind vectors (scale bar in $\mathrm{m} \mathrm{s}^{-1}$ ).

the climatological mean SST, and vertical structures of the atmosphere and ocean, from data rather than attempting to calculate them. For both fluids, we use linear shallow water equations to describe horizontal motions ${ }^{16,17}$ (see Methods). The model atmosphere circulation is driven by radiative relaxation and deep convective heating, calculated using a simple moisture budget. The model SST anomaly is calculated within a uniform-depth mixed layer by balancing SST tendency, horizontal advection, upwelling advection and surface heat fluxes. The ocean sees the atmosphere via surface wind stresses that drive currents and upwelling, and $\mathrm{CO}_{2}$, surface air temperature and humidity that impact the surface heat flux. The atmosphere sees the ocean via SST, which impacts the surface heat fluxes, air humidity and air temperature, which then influence the precipitation and radiation.

We begin with the ocean response to observed forcing. Figure 1d shows the SST in the ocean model forced by changing European Centre for Medium-Range Weather Forecasts (ECMWF) wind stresses $^{18-20}$ and $\mathrm{CO}_{2}$ over 1958-2017. In both observations and this model (Fig. 1a,d), amid widespread $\mathrm{CO}_{2}$-induced warming, the central Pacific cold tongue did not warm. When the ocean model is forced by wind stress changes while $\mathrm{CO}_{2}$ is held constant, the cold tongue cools, indicating a dynamic effect (Fig. 1e). 

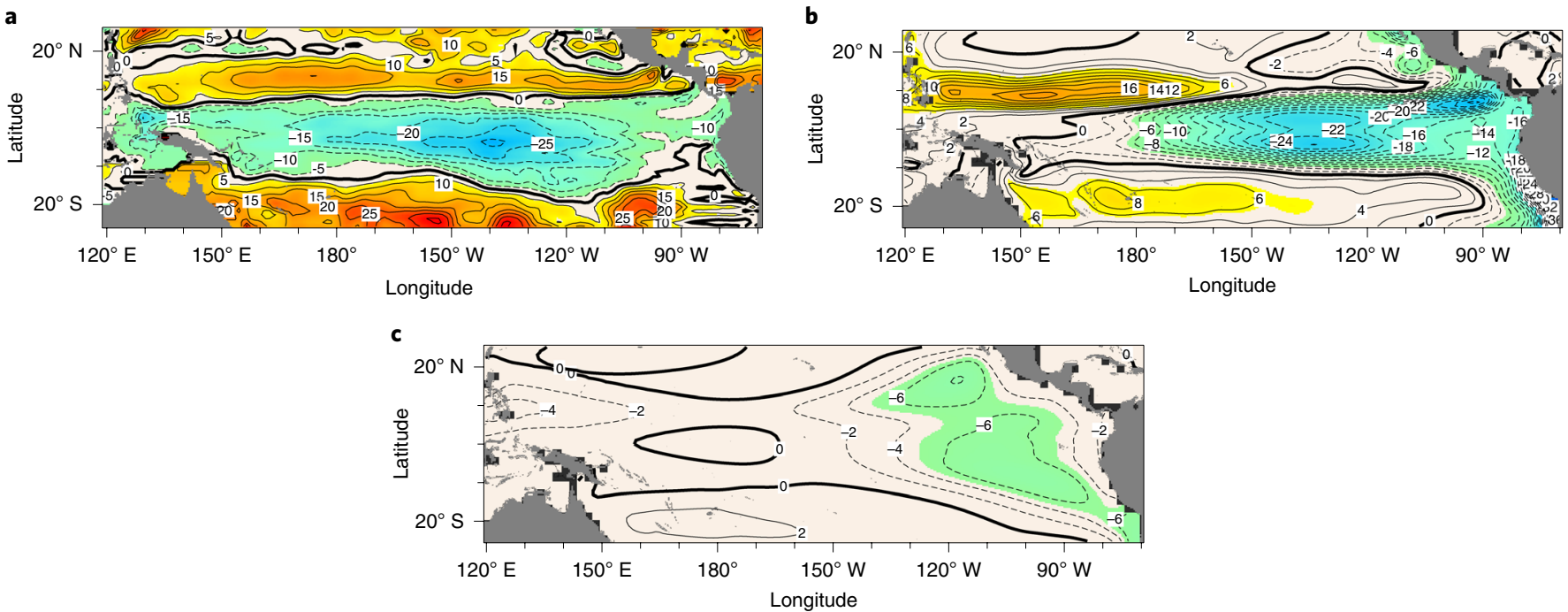

Fig. 4 | Trends in thermocline depth $\left(20^{\circ} \mathrm{C}\right.$ isotherm) over 1958-2017. a-c, Results are shown for ORAS4 (a), the ocean model forced by the same winds used to force ORAS4 (b) and the equilibrium state of our coupled atmosphere-ocean model (c). Units for thermocline depth are in m. The coupled model has more wind-forced zonal asymmetry of the equatorial thermocline change than ORAS4, related to differences in equatorial zonal wind stress change. The simulated shoaling in the upwelling region drives the cooling tendency in the cold tongue, and the basin mean component of shoaling is important and driven by off-equatorial trade wind strengthening.

When $\mathrm{CO}_{2}$ increases but wind stresses are fixed (Fig. 1f), there is warming everywhere, but most where wind speeds are weak (WPWP) and least where wind speeds are strong or there is mean upwelling (regions of weak SST sensitivity to $\mathrm{CO}_{2}$ forcing; see Methods). The observed tropical Pacific SST trend is largely reproduced according to fundamental ocean physics, as a response to rising $\mathrm{CO}_{2}$ and changing wind stress, with the ocean dynamic response causing the lack of cold tongue warming.

Turning to trends in the atmosphere, ECMWF reanalysis (Fig. 2a) shows increased precipitation over the WPWP, decreased precipitation over the north central Pacific, and strengthened north and south trades. In Fig. 2b, we plot the average of trends from three reanalyses only where they all agree on the sign of precipitation change and the quadrant containing the direction of wind change. The increased WPWP precipitation and trade wind strengthening are robust across all three products. The atmosphere model forced by the observed change in SST simulates an increase in WPWP precipitation, decreases in precipitation in the east, and overall strengthening of the north and south trades (Fig. 2c), but fails to produce the meridional wind strength (a common failing of such models $\left.^{21}\right)$. Furthermore, reanalyses have westerlies over the CEP to EEP, but the model has easterlies responding to WPWP precipitation. ECMWF reanalyses, and precipitation and surface pressure data, indicate increased Amazon precipitation during this period. We converted the ECMWF tropical land precipitation into atmosphere heating and impose the trend in the SST-forced atmosphere model (Fig. 2d). A westerly equatorial wind response over the EEP to Amazon heating cancels the easterly anomalies, making wind changes more realistic. Overall, strengthening of the trades and the enhanced WPWP precipitation can be reproduced, according to fundamental atmospheric physics, as a response to the SST change over past decades.

Next, we iteratively coupled the atmosphere and ocean models (see Methods) and computed the response to the change in $\mathrm{CO}_{2}$ alone plus the imposed change in heating over land (Fig. 3). The coupled response has enhanced precipitation over the WPWP, and stronger trade winds. The strengthened winds induce a dynamic cooling tendency in the cold tongue that offsets the $\mathrm{CO}_{2}$-driven warming. Since the imposed Amazon heating simply induces westerlies over the EEP, it is not responsible for the strengthened trends and resulting enhanced equatorial SST gradient, which instead emerge in response to the imposed $\mathrm{CO}_{2}$ forcing.

The shoaling thermocline that causes the simulated cold tongue cooling appears in ocean data (Fig. 4a). The shoaling along the equator is well simulated in our ocean model forced by ECMWF winds (Fig. 4b). The coupled model also simulates shoaling (Fig. 4c), but has more east-west tilt due to stronger westward wind stress on the Equator. However, the zonal mean shoaling is caused by offequatorial trade wind strengthening, consistent with theory ${ }^{22}$.

Our coupled model can be used to understand why state-of-theart models respond to rising GHGs with a greater warming of the cold tongue than elsewhere. To calculate surface heat fluxes and atmospheric moisture convergence, relative humidity is assumed to be spatially uniform in our standard model. If instead we impose the ECMWF distribution, it does not substantially alter the coupled response (Fig. 5a). However, in the CMIP5 multimodel mean relative humidity is too high over the cold tongue (Fig. 5a,b). Also, the CMIP5 climatological wind speed is weaker over the cold tongue than in ECMWF (Fig. 5g,h). When the CMIP5 relative humidity is imposed in our model, the cold tongue warms in response to rising GHGs (Fig. 5b). The response warms by more when the CMIP5 climatological mean wind speed is also imposed in the surface heat flux calculation (Fig. 5c). When additionally the climatological SST in the ocean component is replaced by the CMIP5 climatology, the cold tongue warming in our model closely matches the CMIP5 multimodel mean (Fig. 5d). In this case, the model has no equatorial shoaling of the thermocline (Fig. 5f). We propose that a too-cold cold tongue with warmer water and convergence zones north and south creates, by moisture advection and/or diffusion and wind divergence, a local cold tongue environment of too-high relative humidity and too-low wind speed. These biases create too-high local SST sensitivity to radiative forcing (see Methods). Hence, we argue that cold tongue warming in state-of-the-art models is due to the too-cold cold tongue bias.

Our modelling approach ignores some potentially important large-scale processes, including cloud feedbacks ${ }^{13}$, which are hard to identify in the observational record before the satellite era, and the influence on the tropical Pacific of changes in other basins ${ }^{23}$. 


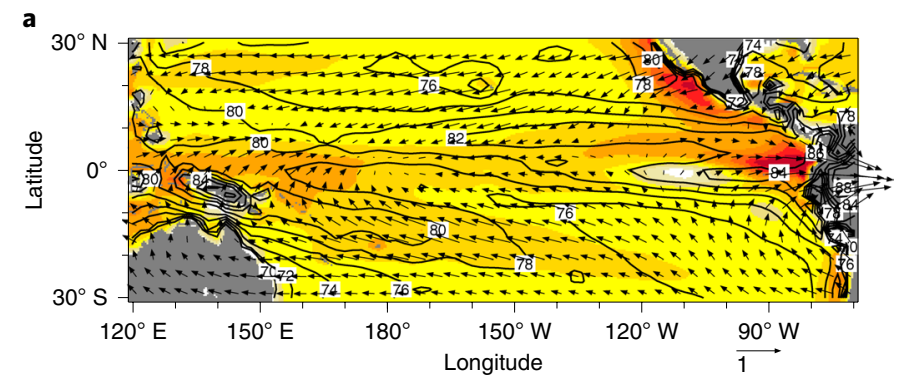

c

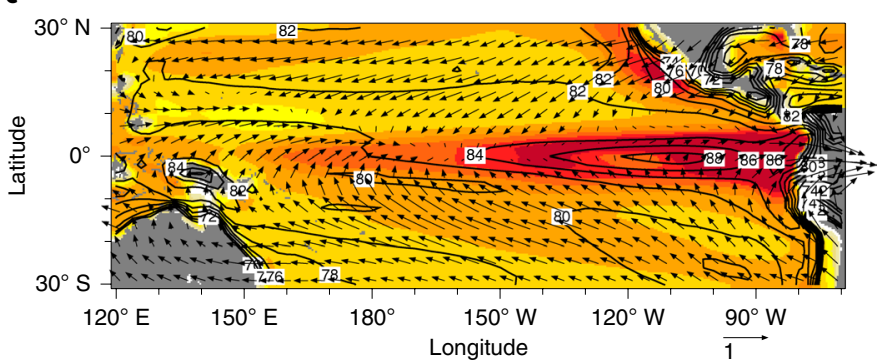

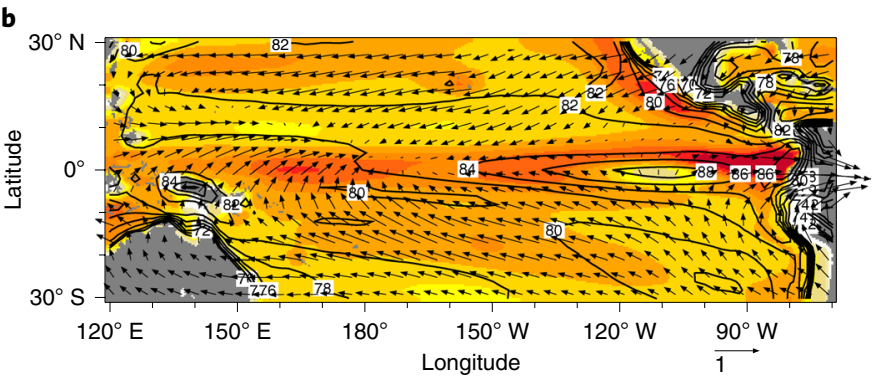

d

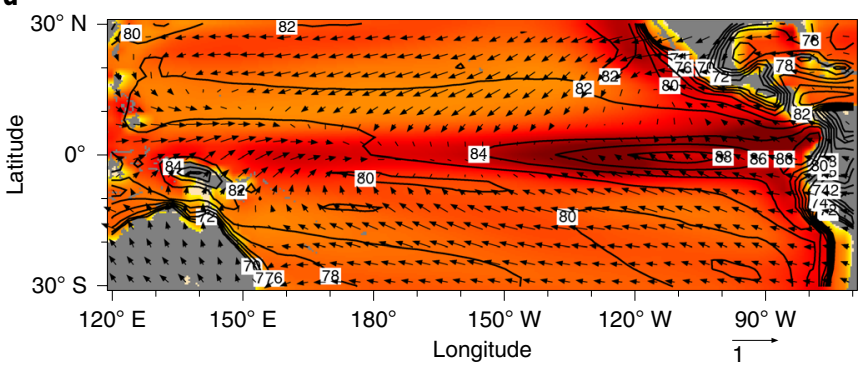

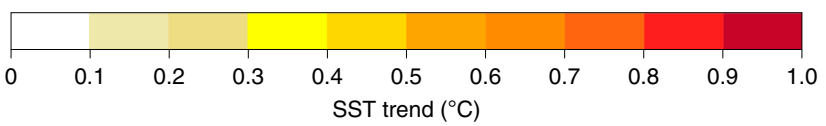

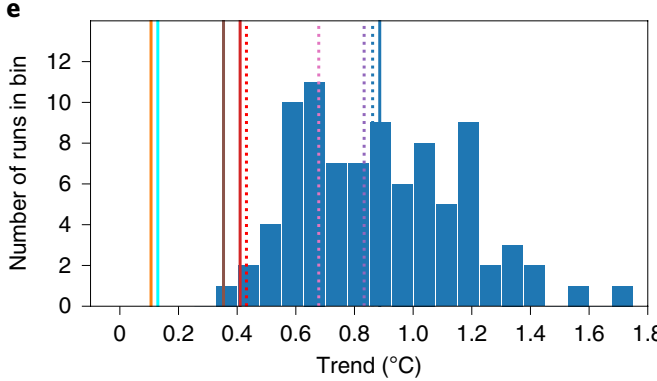

g



f

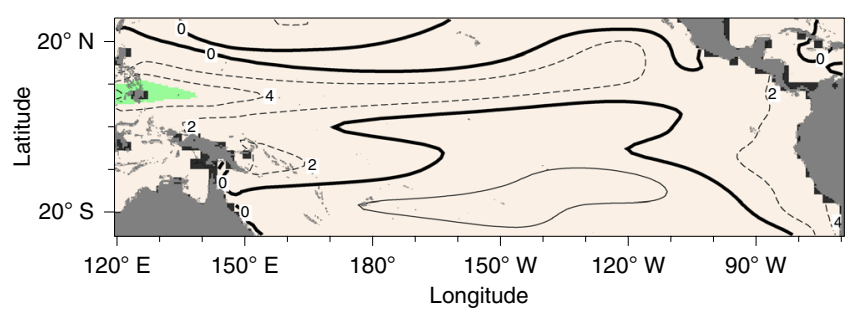

h

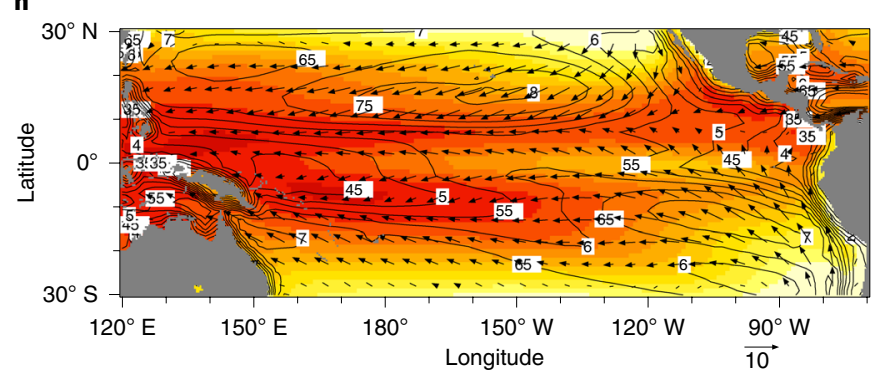

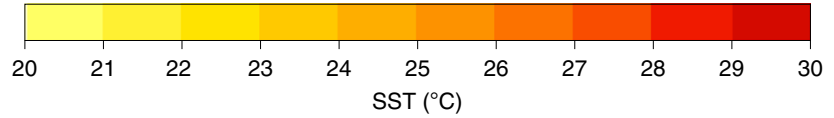

Fig. 5 | Coupled model trends over 1958-2017, and attribution of erroneous trends in CMIP5 models to model bias. a-d, Trends in winds (vectors; scale bar in $\mathrm{m} \mathrm{s}^{-1}$ ) and SST (colours; see scale bar) over 1958-2017 within the coupled model (CM), moving from the observed world to the CMIP5 world. In a, the observed spatially varying relative humidity (\%, contours) from ECMWF is imposed in the model instead of a uniform value ('CM-ECMWF world' in e). In b, the CMIP5 multimodel mean spatially varying relative humidity (\%, contours in $\mathbf{b}-\mathbf{d}$ ) is imposed ('CM-ECMWF C-RH' in e). In c, the CMIP5 wind speed is also imposed ('CM-ECMWF C-RH W' in e). Finally, in d, the ocean model is additionally ' $\mathrm{q}$-fluxed' towards the CMIP5 multimodel mean SST climatology ('CM-CMIP5 world' in e). e, Histogram of trends in the NINO3.4 SST index in 88 individual CMIP5 model runs, together with the trends from HadISST, NCEP/NCAR, ERSSTV5 and ECMWF ORAS4 SST analyses, and our coupled model setups described in a-d. The observed SST trends

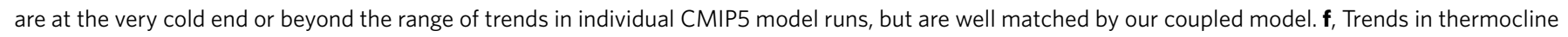
depth (m). g,h, Climatological winds (vectors; scale bar in $\mathrm{ms}^{-1}$ ), SST (colours; see scale bar) and wind speed ( $\mathrm{ms} \mathrm{s}^{-1}$ contours and numerical labels) for ECMWF (g) and the CMIP5 multimodel mean (h). Incorporating from the CMIP5 multimodel mean the climatological relative humidity, which is biased high over the cold tongue (a and $\mathbf{b}$ ), and wind speed, which is biased low over the cold tongue ( $\mathbf{g}$ and $\mathbf{h}$ ), allows our coupled model to match the CMIP5 multimodel mean trend well. 
The thermocline structure is fixed in the model, while in nature it could change as the waters that flow into the equatorial thermocline from the subtropics ${ }^{24}$ warm. However, this is likely to remain a small influence on the temperature of upwelling water relative to the effect of the wind-driven thermocline shoaling identified here. This is a consequence of the equatorial thermocline being so sharp that even small vertical displacements result in substantial temperature changes. These caveats notwithstanding, the reproduction of key features of observed change by a parsimonious tropical Pacificcentred model suggests that these changes are largely due to local dynamic coupling.

The main features of observed tropical Pacific climate change over past decades are consistent with a response to rising $\mathrm{CO}_{2}$, according to fundamental atmosphere and ocean physics. The spatial pattern of climatological upwelling and wind speeds means rising $\mathrm{CO}_{2}$ causes more warming over the western than CEP, driving stronger trade winds that shoal the thermocline, which cools the cold tongue, further strengthening the zonal SST gradient and, hence, the trades. Delayed warming of the thermocline could oppose this positive feedback but, to date, has not cancelled it. This response favours enhanced (diminished) convection over the west (central) equatorial Pacific akin to La Niña events and will drive La Niña-like climate trends worldwide (drying in East Africa, southwest North America and southeast South America, and wetting in Southeast Asia, Northeast Brazil and the Sahel). These tropical Pacific-driven precipitation changes will compete against other sources of variability and radiatively driven change $e^{25,26}$. However, the strength of the tropical Pacific influence on global climate implies that past and future trends will diverge from those simulated by coupled climate models that, due to their cold tongue bias, misrepresent the response of the tropical Pacific to rising $\mathrm{CO}_{2}$. Until state-of-the-art models more faithfully represent the observed tropical Pacific, climate impact assessments should consider the consequences for the global hydroclimate of continuing La Niña-like trends in tropical Pacific SSTs.

\section{Online content}

Any methods, additional references, Nature Research reporting summaries, source data, statements of code and data availability and associated accession codes are available at https://doi.org/10.1038/ s41558-019-0505-x.

Received: 24 December 2018; Accepted: 10 May 2019;

Published online: 24 June 2019

\section{References}

1. Bjerknes, J. Atmospheric teleconnections from the equatorial Pacific. Mon Weather Rev. 97, 162-172 (1969).

2. Dai, A. \& Wigley, T. M. L. Global patterns of ENSO-induced precipitation. Geophys. Res. Lett. 27, 1283-1286 (2000).

3. Trenberth, K. E. et al. Progress during TOGA in understanding and modeling global teleconnections associated with tropical sea surface temperature. J. Geophys. Res. 103, 14291-14324 (1998).

4. Kosaka, Y. \& Xie, S.-P. Recent global-warming hiatus tied to equatorial Pacific surface cooling. Nature 501, 403-407 (2013).

5. Coats, S. \& Karnauskas, K. B. Are simulated and observed twentieth century tropical Pacific sea surface temperature trends significant relative to internal variability? Geophys. Res. Lett. 44, 9928-9937 (2017).

6. Zebiak, S. E. \& Cane, M. A. A model El Niño-Southern Oscillation. Mon. Weather Rev. 115, 2262-2278 (1987).

7. Delworth, T. L., Zeng, F., Rosati, A., Vecchi, G. A. \& Wittenberg, A. A link between the hiatus in global warming and North American drought. J. Clim. 28, 3834-3845 (2015).

8. Yang, W., Seager, R., Cane, M. A. \& Lyon, B. The East African long rains in observations and models. J. Clim. 27, 7186-7202 (2014).

9. Clement, A. C., Seager, R., Cane, M. A. \& Zebiak, S. E. An ocean dynamical thermostat. J. Clim. 9, 2190-2196 (1996).
10. Cane, M. A. et al. Twentieth century sea surface temperature trends. Science 275, 957-960 (1997).

11. Knutson, T. R. \& Manabe, S. Time-mean response over the tropical pacific to increased $\mathrm{CO}_{2}$ in a coupled ocean-atmosphere model. J. Clim. 8, 2181-2199 (1995).

12. Vecchi, G. A. \& Soden, B. J. Global warming and the weakening of the tropical circulation. J. Clim. 20, 4316-4340 (2007).

13. Li, G., Xie, S.-P., Du, Y. \& Luo, Y. Effects of excessive equatorial cold tongue bias on the projections of tropical Pacific climate change. Part I: the warming pattern in CMIP5 multi-model ensemble. Clim. Dynam. 47, 3817-3831 (2016)

14. Li, G. \& Xie, S. P. Tropical biases in CMIP5 multimodel ensemble: the excessive equatorial Pacific cold tongue and double ITCZ problems. J. Clim. 27, 1765-1780 (2014).

15. Luo, J.-J., Wang, G. \& Dommenget, D. May common model biases reduce CMIP5's ability to simulate the recent Pacific La Niña-like cooling? Clim. Dynam. 50, 1335-1351 (2018).

16. Gill, A. E. Some simple solutions for heat-induced tropical circulation. Q. J. R. Meteor. Soc. 106, 447-462 (1980).

17. Blumenthal., M. B. \& Cane, M. A. Accounting for parameter uncertainties in model verification: an illustration with tropical sea surface temperature. J. Phys. Oceanogr. 19, 815-830 (1989).

18. Uppala, S. M. et al. The ERA-40 re-analysis. Q. J. R. Meteor. Soc. 131, 2961-3012 (2005).

19. Dee, D. P. et al. The ERA-Interim reanalysis: configuration and performance of the data assimilation system. Q. J. R. Meteor. Soc. 137, 553-597 (2011).

20. Balmaseda, M. A., Mogensen, K. \& Weaver, A. T. Evaluation of the ECMWF ocean reanalysis system ORAS4. Q. J. R. Meteor. Soc. 139 1132-1161 (2013)

21. Chiang, J. C. H., Zebiak, S. E. \& Cane, M. A. Relative roles of elevated heating and surface temperature gradients in driving anomalous surface winds over tropical oceans. J. Clim. 58, 1371-1394 (2001).

22. Emile-Geay, J. \& Cane, M. A. Pacific decadal variability in the view of linear equatorial wave theory. J. Phys. Oceanogr. 39, 203-219 (2009).

23. Hu, S. \& Federov, A. V. Cross-equatorial winds control El Niño diversity and change. Nat. Clim. Change 8, 798-802 (2018).

24. Burls, N. J. \& Federov, A. V. What controls the mean East-West sea surface temperature gradient in the equatorial Pacific: the role of cloud albedo. J. Clim. 27, 2757-2778 (2014).

25. Seager, R., Naik, N. \& Vecchi, G. A. Thermodynamic and dynamic mechanisms for large-scale changes in the hydrological cycle response to global warming. J. Clim. 23, 4651-4668 (2010).

26. Wu, Y. \& Polvani, L. M. P. Contrasting short- and long-term projections of the hydrological cycle in the southern extratropics. J. Clim. 28, 5845-5856 (2015)

\section{Acknowledgements}

This work was supported by NSF award OCE 1657209 and a grant from World Surf League P.U.R.E. through Columbia University's Center for Climate and Life. We thank R. Miller, B. Fox-Kemper, T. Shepherd, R. Chadwick, J. Smerdon, P. Williams and I. Simpson for useful discussions.

\section{Author contributions}

R.S. conceived of the study and directed the research. All authors designed the experiments. R.S. and M.C. designed the atmosphere and ocean thermodynamic models. N.H. and M.C. designed the numerical methods for solution, with assistance from R.S. N.H. wrote the new model codes, implemented the ocean model and conducted the modelling. D.-E.L. and N.H. led the analysis of ocean and atmosphere data. D.-E.L. conducted experiments with the ocean model to interpret the results. R.S. wrote the paper, with all authors contributing advice on content and wording.

\section{Competing interests}

The authors declare no competing interests.

\section{Additional information}

Reprints and permissions information is available at www.nature.com/reprints. Correspondence and requests for materials should be addressed to R.S.

Peer review information: Nature Climate Change thanks Natalie Burl and the other, anonymous, reviewer(s) for their contribution to the peer review of this work.

Publisher's note: Springer Nature remains neutral with regard to jurisdictional claims in published maps and institutional affiliations.

(C) The Author(s), under exclusive licence to Springer Nature Limited 2019 


\section{Methods}

Atmosphere and ocean reanalyses. For observations of surface winds at $2 \mathrm{~m}$, precipitation, SST and thermocline depth, we used reanalyses from the European Centre for Medium Range Weather Forecasts (ECMWF). For the atmosphere, we combined ECMWF Reanalysis-40 (ERA-40), (ref. ${ }^{18}$ ) from 1958-1978 (available at http://apps.ecmwf.int/datasets/data/era40-daily/levtype $=$ sfc/) and ECMWF Reanalysis-Interim (ERA-Interim) ${ }^{19}$ from 1979-2017 (available at https://www. ecmwf.int/en/forecasts/datasets/archive-datasets/reanalysis-datasets/era-interim). For the ocean, we used the ocean reanalysis system 4 (ORAS4) ${ }^{20}$ (available at https://www.ecmwf.int/en/research/climate-reanalysis/ocean-reanalysis), which began in 1958 and dictated that the period studied was 1958-2017. Thermocline depth is represented by the depth of the $20^{\circ} \mathrm{C}$ isotherm.

Atmosphere model. The atmosphere model ${ }^{16,27-29}$ assumes that zonal, $u$, meridional, $v$, and vertical, $w$, velocity are described by a single vertical mode as $(u, v, w)=\left(u^{\prime} \cos \left(\pi z / z_{\mathrm{T}}\right), v^{\prime} \cos \left(\pi z / z_{\mathrm{T}}\right), w^{\prime} \sin \left(\pi z / z_{\mathrm{T}}\right)\right)$, where $z$ is height and $z_{\mathrm{T}}$ is the top of the troposphere. Similarly, potential temperature, $\theta$, and heating, $Q$, vary as $(\theta, Q)=\left(\theta^{\prime}, Q^{\prime}\right)\left(\theta_{0} / \theta_{00}\right) \sin \left(\pi z / z_{\mathrm{T}}\right)$ and pressure, $p$, varies as $p=p^{\prime}\left(\rho_{0} / \rho_{00}\right) \cos$ $\left(\pi z / z_{\mathrm{T}}\right) . \theta_{0}$ and $\rho_{0}$ are basic-state potential temperature and density profiles, with the subscript ' 00 ' indicating surface values. Using subscript notation for partial derivatives and the anelastic approximation, $\left(p / \rho_{0}\right)_{z}=g \theta / \theta_{00}$, the hydrostatic relation is $p^{\prime} / \rho_{00}=\left(g z_{\mathrm{T}} / \pi \theta_{00}\right) \theta^{\prime}$. Together, with $x, y$, and $t$ subscripts indicating derivatives, these allow the following zonal and meridional momentum equations, and combined continuity and thermodynamic equation:

$$
\begin{gathered}
\varepsilon_{u} u-f v+\phi_{x}=0 \\
\varepsilon_{v} v+f u+\phi_{y}=0 \\
\varepsilon_{\phi} \phi+u_{x}+v_{y}=-Q_{1}
\end{gathered}
$$

where primes have been dropped, $f$ is the Coriolis parameter, $\Phi$ is the geopotential $\left(\Phi=-\left(g z_{\mathrm{T}} / \pi \theta_{00}\right) \theta\right)$, and $\varepsilon_{u}$ and $\varepsilon_{v}$ refer to the Rayleigh friction. $\varepsilon_{\Phi}$ is related to a Newtonian cooling rate, $K$, by $\varepsilon_{\phi}=K \pi^{2} /\left(N^{2} z_{\mathrm{T}}^{2}\right)$, where $N^{2}$ is a specified buoyancy frequency. $Q_{1}$ is a modified heating and drives the winds. It is given by:

$$
Q_{1}=\frac{g \pi}{N^{2} \theta_{00} z_{\mathrm{T}}}\left(K \theta_{\mathrm{s}}+Q_{\mathrm{c}}\right)
$$

This includes a radiative relaxation of $\theta$ to a mid-troposphere potential temperature, $\theta_{s}$, related by a moist adiabat to the SST, and a convective heating part, $Q_{c} \cdot Q_{1}$ is a modified heating since the part involving $\theta$ is on the left-hand side. $Q_{\mathrm{c}}$ is related to precipitation, $P$, by $Q_{\mathrm{c}}=\left(\pi L / 2 c_{\mathrm{pa}} \bar{\rho} z_{\mathrm{T}}\right) P$, where $\bar{\rho}$ is an air density characteristic of the troposphere, $L$ is the latent heat of evaporation and $c_{\mathrm{pa}}$ is the specific heat capacity of air. $P$ must be positive and is computed from evaporation minus the vertically integrated moisture divergence:

$$
P=\rho_{\mathrm{a}} c_{\mathrm{E}} W\left(q_{\mathrm{s}}-q_{\mathrm{a}}\right)-\rho_{\mathrm{a}} H_{\mathrm{q}} \nabla \cdot \mathbf{u} q_{\mathrm{a}}
$$

Here, $W$ is the climatological surface wind speed from ECMWF, $c_{\mathrm{E}}$ is an exchange coefficient, $\rho_{\mathrm{a}}$ is the surface air density, $H_{\mathrm{q}}$ is a scale depth for moisture, $\mathbf{u}$ is the vector surface wind, and $q_{\mathrm{a}}$ is the surface-specific humidity, which equals $r q_{\mathrm{s}}\left(T_{\mathrm{s}}\right)$, where $r$ is the 'effective' relative humidity and $q_{\mathrm{s}}\left(T_{\mathrm{s}}\right)$ is the saturation-specific humidity at the SST, $T_{s}$.

Ocean model. The upper-ocean circulation is represented by frictional, timedependent, linear, shallow water equations for the first two baroclinic vertical modes $(m=1,2)$ forced by surface wind stress ${ }^{17}$ :

$$
\begin{gathered}
r_{m} u_{m}+u_{m t}-f v_{m}=-g h_{m x}+\tau_{m}^{x} \\
r_{m} v_{m}+v_{m t}+f u_{m}=-g h_{m y}+\tau_{m}^{y} \\
r_{m} h_{m}+h_{m t}+u_{m x}+v_{m y}=0
\end{gathered}
$$

Here, $u_{m}, v_{m}, h_{m}, \tau_{m}^{x}$ and $\tau_{m}^{y}$ are non-dimensional zonal and meridional currents, thermocline depth, and zonal and meridional surface wind stress for vertical mode $m$, and $r_{m}$ is a damping rate for mode $m$. Dimensional equations and variables are given by multiplying velocities by $U$, length by $H$ and stress by $U / T$, where $U=c_{m}, H=c_{m}^{2} / g$ and $T=\left(c_{m} \beta\right)^{-1 / 2}$ are the velocity, depth and time scales, with $c_{m}$ the modal wave speed, $g$ the acceleration due to gravity and $\beta=\mathrm{d} f / \mathrm{d} y$. The surface wind stress is directly felt within a surface Ekman layer of uniform depth, $H_{\mathrm{s}}=50 \mathrm{~m}$ driving zonal and meridional currents $u_{\mathrm{E}}$ and $v_{\mathrm{E}}$ :

$$
r_{\mathrm{E}} u_{\mathrm{E}}-f v_{\mathrm{E}}=\tau^{x} / \rho H^{*}
$$

$$
r_{E} v_{E}+f u_{E}=\tau^{y} / \rho H^{*}
$$

where $\rho$ is the density of water. $H^{*}>H_{\mathrm{s}}$ is given by $1 / H^{*}=1 / H_{\mathrm{s}}-1 / D_{1}-1 / D_{2}$, where $D_{1}$ and $D_{2}$ are effective depths for the forcing of the two baroclinic modes we retain. Note that $H^{*}$ appears in equations (9) and (10) instead of $H_{\mathrm{s}}$ to remove the part of the wind stress driving the two baroclinic modes. For details and justification, see Appendix A of ref. ${ }^{17}$. The surface mixed-layer currents $u_{\mathrm{s}}$ and $v_{\mathrm{s}}$ add the residual Ekman component, $u_{\mathrm{E}}$ and $v_{\mathrm{E}}$, to the surface flow given by the shallow water solution and prescribed modal structures ${ }^{17}$. Then, the upwelling at the mixed-layer base, $w_{s}$, is given by:

$$
w_{\mathrm{s}}=H_{\mathrm{s}}\left(u_{\mathrm{s} x}+v_{\mathrm{s} y}\right)
$$

The SST in the mixed layer, $T_{\mathrm{s}}$, is given by:

$$
\frac{\partial T_{\mathrm{s}}}{\partial t}+\mathbf{u}_{\mathrm{s}} \cdot \nabla T_{\mathrm{s}}+M\left(w_{\mathrm{s}}\right) \gamma \frac{\left(T_{\mathrm{s}}-T_{\mathrm{d}}\right)}{H_{\mathrm{s}}}=-\frac{1}{\rho c_{\mathrm{pw}} H_{\mathrm{s}}}\left(\bar{Q}+Q^{\prime}\right)
$$

Here, $M\left(w_{\mathrm{s}}\right)=w_{\mathrm{s}}$ if $w_{\mathrm{s}} \geq 0$ and 0 if $w_{\mathrm{s}}<0$ since only upwelling influences SST. $\bar{Q}$ and $Q^{\prime}$ are the climatological and perturbation net surface heat flux, both positive upward, $T_{\mathrm{d}}$ is temperature below the mixed layer, and $\gamma$ is an efficiency of entrainment so that entrained water has temperature $\gamma T_{\mathrm{d}}+(1-\gamma) T_{\mathrm{s}}$, and $c_{\mathrm{pw}}$ is the specific heat capacity of water. The model is run forced by climatological winds to compute the $\bar{Q}$ (typically referred to as the 'Q-flux') that is needed for the model to produce the climatological SST, $\bar{T}_{\mathrm{s}}$ in the presence of climatologically modelled $\mathbf{u}_{\mathrm{s}}, w_{\mathrm{s}}, h_{20}$, where $h_{20}$ is the depth of the thermocline (given by the $20^{\circ} \mathrm{C}$ isotherm) $T_{\mathrm{d}}=T_{\mathrm{d}}\left(h_{20}\right)$ is computed from a cubic spline fit between the equatorial Pacific data for ORAS4 temperature at $50 \mathrm{~m}$ depth and the model thermocline depth, ensuring a well-resolved thermocline structure to influence SST via $T_{\mathrm{d}}^{30}$.

Surface heat flux. It is assumed that the surface heat flux anomaly is dominated by longwave and latent heat fluxes and that the solar radiation does not change and the sensible heat flux anomaly is small. The air temperature is given by $T_{\mathrm{a}}=T_{\mathrm{s}}-\Delta T$, and $q_{\mathrm{a}}$ is given in terms of SST as above. Then, the latent and longwave heat flux anomalies, $Q_{\mathrm{LH}}^{\prime}$ and $Q_{\mathrm{LW}}^{\prime}$, are computed from bulk formulae $\mathrm{e}^{17,30}$ and, after linearizing around the mean SST, $\bar{T}_{\mathrm{s}}$, are given by:

$$
Q_{\mathrm{LH}}^{\prime}=\left.\rho_{\mathrm{a}} C_{\mathrm{E}} W L(1-r) \frac{\mathrm{d} q_{\mathrm{s}}}{\mathrm{d} T_{\mathrm{s}}}\right|_{T_{\mathrm{s}}} T_{\mathrm{s}}^{\prime}
$$

$$
Q_{\mathrm{LW}}^{\prime}=\varepsilon \sigma \bar{T}_{\mathrm{s}}^{4} f_{1}^{\prime}\left(1-a C^{2}\right)+\left.\frac{\mathrm{d} Q_{\mathrm{LW}}}{\mathrm{d} T_{\mathrm{s}}}\right|_{T_{\mathrm{s}}} T_{\mathrm{s}}^{\prime}
$$

where $L$ is the latent heat of vapourization, $\sigma$ is the Stefan-Boltzmann constant, $\varepsilon$ is the emissivity of water, $C$ is the cloud cover and $a$ is a parameter. $f_{1}^{\prime}$ is the anomaly in $f_{1}$-a parameter that can be adjusted to control the variation in surface longwave radiation due to a change in $\mathrm{CO}_{2}$. W is again the climatological annual mean wind speed, which is taken from ECMWF reanalysis for our standard model and from the CMIP5 multimodel mean when examining causes of bias in the CMIP5 models.

The derivative of net surface longwave radiation with $T_{\mathrm{s}}$, evaluated for climatological conditions denoted by overbars, is:

$$
\left.\frac{\mathrm{d} Q_{\mathrm{LW}}}{\mathrm{d} T_{\mathrm{s}}}\right|_{T_{\mathrm{s}}}=\left(1-a \bar{C}^{2}\right) \varepsilon \sigma \bar{T}_{\mathrm{s}}^{3}\left[4 f_{1}-f_{2}\left(\frac{\bar{q}_{\mathrm{a}} \bar{p}_{\mathrm{s}}}{0.622}\right)^{1 / 2}\left(\left.\frac{\bar{T}_{\mathrm{s}}}{2 \bar{q}_{\mathrm{s}}} \frac{\mathrm{d} q_{\mathrm{s}}}{\mathrm{d} T}\right|_{T_{\mathrm{s}}}+4\right)\right]+12 \varepsilon \sigma \bar{T}_{\mathrm{s}}^{2} \Delta T
$$

where $f_{2}$ is a parameter that controls the strength of the water vapour radiative feedback, and $p_{s}$ is the surface pressure.

SST sensitivity to $\mathrm{CO}_{2}$ forcing. For illustrative purposes only, combining the SST and surface heat flux equations, and neglecting the term nonlinear in upwelling and ocean temperature, gives the equilibrium SST equation:

$$
\begin{aligned}
& {\left[\frac{M\left(\overline{w_{\mathrm{s}}}\right) \gamma}{H}+\frac{1}{\rho c_{\mathrm{pw}} H}\left(\left.\frac{\mathrm{d} Q_{\mathrm{LW}}}{\mathrm{d} T_{\mathrm{s}}}\right|_{\bar{T}_{\mathrm{s}}}+\left.\rho_{\mathrm{a}} C_{\mathrm{E}} W L(1-r) \frac{\mathrm{d} q_{\mathrm{s}}}{\mathrm{d} T_{\mathrm{s}}}\right|_{T_{\mathrm{s}}}\right)+\mathbf{u} \cdot \nabla\right] T_{\mathrm{s}}^{\prime}=} \\
& -\mathbf{u}^{\prime} \cdot \nabla \bar{T}_{\mathrm{s}}-\left[M\left(\bar{w}_{\mathrm{s}}+w_{\mathrm{s}}^{\prime}\right)-M\left(\bar{w}_{\mathrm{s}}\right)\right] \gamma \frac{\left(\bar{T}_{\mathrm{s}}-\bar{T}_{\mathrm{d}}\right)}{H} \\
& +M\left(\overline{w_{\mathrm{s}}}\right) \gamma \frac{T_{\mathrm{d}}^{\prime}}{H}-\frac{1}{\rho c_{\mathrm{pw}} H} \varepsilon \sigma \bar{T}_{\mathrm{s}}^{4} f_{1}^{\prime}\left(1-a C^{2}\right)
\end{aligned}
$$

This provides $T_{s}^{\prime}$ in terms of the mean upwelling, mean vertical temperature profile, anomalous upwelling, anomalous thermocline temperature, mean 
temperature, wind speed and cloud cover, and change in GHG forcing in the longwave radiation $\left(f_{1}^{\prime}\right)$. It accounts for the water vapour-longwave feedback (the negative terms in equation (15) that tend to reduce longwave cooling as $T_{\mathrm{s}}$ increases) and how changes in water vapour influence latent cooling of the surface. Under increasing $\mathrm{CO}_{2}, f_{1}^{\prime}<0$, leading to $T_{\mathrm{s}}^{\prime}>0$. The warming will be least (most) where the square-bracketed term on the left hand side will be largest (smallest) that is, for warm (cool), windy (calm) and/or upwelling (downwelling). Also, anomalous upwelling, $w_{\mathrm{s}}^{\prime}>0$, and a cooling thermocline, $T_{\mathrm{d}}^{\prime}<0$, would induce a cooling tendency to offset warming. Furthermore, if relative humidity is spatially variable, warming will be most where it is high. $f_{1}^{\prime}$ was set to provide an increase in downward longwave radiation to the ocean equivalent to that caused by the change in $\mathrm{CO}_{2}$ over 1958-2017 in the absence of any change in atmospheric $T_{\mathrm{a}}$ or $q_{\mathrm{a}}$ (that is, the direct $\mathrm{CO}_{2}$ radiative forcing).

Model solution method. The atmosphere equations are solved by Fourier transforming in longitude, forming an equation for $v$ for each zonal wavenumber that is finite differenced, and the resulting tri-diagonal system is solved by matrix inversion, transforming back into longitude. Finally, $u$ and $\Phi$ are derived by backsubstitution. The ocean equations are solved using the 'INC' scheme ${ }^{31}$, integrating the model forward, after spin-up with climatological conditions, forced by the time-varying ECMWF wind stress and, for the case with $\mathrm{CO}_{2}$ forcing, changing $f_{1}^{\prime}$ in the net surface longwave radiation calculation. Change over 1958-2017 is computed by a linear trend. The atmosphere model is solved forced by a $T_{s}$ comprised of the climatological mean for 1958-2017 plus and minus half of the SST trend and the difference of the two simulations taken to derive the change. For the coupled model, the ocean model is first forced with the change in $\mathrm{CO}_{2}$ and climatological wind stress over 1958-2017. The resulting SST trend, plus the imposed heating change over land, are used to force the atmosphere model. The ocean model is forced again with both the changed wind stress and the $\mathrm{CO}_{2}$ increase to derive a new SST change over 1958-2017 that is then used to force the atmosphere model. This iterative coupling is repeated until equilibrium is reached, which takes just a few times. There is a unique solution for any given value of $\mathrm{CO}_{2}$. The model wind stress change is computed as $\rho_{\mathrm{a}} c_{\mathrm{D}} W \mathbf{u}$, where $c_{\mathrm{D}}$ is a drag coefficient and $\mathbf{u}$ is the vector surface wind change computed by the atmosphere model, which is added to the ECMWF climatological stresses. Since the atmosphere model dynamics are only applicable in the tropics, the computed wind stress anomaly is only applied to the ocean model between $20^{\circ} \mathrm{S}$ and $20^{\circ} \mathrm{N}$, and is linearly tapered to zero at $25^{\circ} \mathrm{S}$ and $25^{\circ} \mathrm{N}$.

Precipitation trends over land, and assessment of uncertainty in reanalyses. The ECMWF reanalyses indicate a wetting trend over the Amazon, and the atmospheric response to the associated heating improves model simulation of winds over the EEP Ocean. To check the validity of the wet trend, we examined surface pressure data from the Hadley Center (https://www.metoffice.gov.uk/ hadobs/hadslp2/) and rain gauge data from the Climatic Research Unit Time Series version 3.25 (https://crudata.uea.ac.uk/cru/data/hrg/). Consistent with ECMWF, these data show a tendency towards lower surface pressure and wetter conditions. Since the agreement between our model and ECMWF reanalyses over 1958-2017 is far from perfect, it is necessary to consider possible reasons why. Data quality/availability is one reason. Direct observations of SST and surface winds over the tropical Pacific are restricted to ships of opportunity in the earlier decades and few trading routes cross the CEP to EEP. Subsurface observations are even sparser for the period before the advent of Argo floats in the late $1990 \mathrm{~s}^{32}$. The advent of satellite data in the 1970s, and then floats, created potential spurious jumps in observed quantities that compromise trends. Assimilation schemes vary, and different SST and wind products and reanalyses can provide quite different ocean and atmosphere states, even when handling essentially the same data. We examined changes in thermocline depth in the Simple Ocean Data Assimilation reanalysis $^{33}$ (available at http://apdrc.soest.hawaii.edu/dods/public_data/SODA/ soda_pop2.2.4.info) and analyses of ocean data $^{32,34}$ (available at https://rda.ucar. edu/datasets/ds285.3/ and https://www.metoffice.gov.uk/hadobs/en4/data/en4-2$0 /$ ). All show shoaling of the equatorial thermocline, although by lesser amounts than ORAS4. We examined wind changes in the Japanese Meteorological Agency 55-year Reanalysis ${ }^{35}$ (available at https://rda.ucar.edu/datasets/ds628.0/) and the National Oceanic and Atmospheric Administration Twentieth Century Reanalysis ${ }^{36}$ (available at https://rda.ucar.edu/datasets/ds131.2/), which only assimilates surface pressure data, reducing the risk of spurious trends due to changes in observing methods and practices. Trade wind strengthening, primarily in the Southern Hemisphere, is clear in all three reanalyses (Fig. 2). A further source of difference between our model and reanalyses is that they operate according to different physical laws. Complex vertical structure, nonlinear dynamics, subtle connections between SSTs, atmosphere convection, ocean mixing and boundary-layer dynamics are all possible in the Reanalyses but not in the our model, and maybe influence details of the trends.

CMIP5 models and NCAR LENS. The SST trend from state-of-the-art coupled climate models was computed for the multimodel mean of, and 85 individual runs from, 40 models from CMIP5, using the historical simulations from 1958-2005 and the Representative Concentration Pathway 8.5 projections from 2006-2017 $7^{37}$.
Simulations that were continuous from the historical simulation to the projections were used from each model. The multimodel mean was computed as the average of the 85 individual runs. The CMIP5 data were collected from https://cmip. llnl.gov/cmip5/data_portal.html. The SST data for the 40 models regridded to a common $1^{\circ} \times 1^{\circ}$ grid are available at http://kage.ldeo.columbia.edu:81/ SOURCES/.LDEO/.ClimateGroup/.PROJECTS/.IPCC/.CMIP5/.m40mmm_1x1/. In addition, we examined SST trends from the NCAR LENS, which includes 35 ensemble members ${ }^{38}$, and collected data from http://www.cesm.ucar.edu/projects/ community-projects/LENS/data-sets.html.

SST analyses. To compare the modelled trend with estimates of the observed trend, in addition to that derived from ORAS4, we analysed SST trends from the Hadley Center Sea Ice and SST (HadISST) data ${ }^{39}$ (available at https://www. metoffice.gov.uk/hadobs/hadisst/), the National Centers for Environmental Prediction/NCAR Reanalysis 1 (ref. ${ }^{40}$; available at https://iridl.ldeo.columbia. edu/SOURCES/.NOAA/.NCEP-NCAR/.CDAS-1/) and the National Oceanic and Atmospheric Administration Extended Reconstructed SST version 5 (ERSSTv5) ${ }^{41}$ (available at https://www.ncdc.noaa.gov/data-access/marineocean-data/extendedreconstructed-sea-surface-temperature-ersst-v5).

Model parameter values and constants. The atmosphere and ocean models require a number of parameter values and constants to be set.

For the ocean and surface heat flux model, these are as follows: $\gamma=0.75$; $H_{\mathrm{s}}=50 \mathrm{~m} ; H^{*}=72.9 \mathrm{~m} ; \rho=1,024 \mathrm{~kg} \mathrm{~m}^{-3} ; c_{\mathrm{pw}}=4,184 \mathrm{~J} \mathrm{~kg}^{-1} \mathrm{~K}^{-1} ; \varepsilon=0.97$; $\sigma=5.67 \times 10^{-8} ; f_{1}=0.39 ; f_{2}=0.05 ; a=0.4$ if $T_{s} \geq 28^{\circ} \mathrm{C} ; a=0.8$ if $T_{s}<28^{\circ} \mathrm{C}$; $\rho_{\mathrm{a}}=1.225 \mathrm{~kg} \mathrm{~m}^{-3} ; C_{\mathrm{E}}=0.00125 ; L=2.5 \times 10^{6} \mathrm{Jkg}^{-1} ; \Delta T=1 \mathrm{~K} ; r_{\mathrm{E}}=2 \mathrm{~d}^{-1} ; r_{m}=3.5 \mathrm{yr}^{-1}$; $c_{1}=2.98 \mathrm{~m} \mathrm{~s}^{-1}$; and $c_{2}=1.85 \mathrm{~m} \mathrm{~s}^{-1}$. The effective relative humidity, $r$, is assumed to be spatially uniform at 0.80 in our standard model. In considering the cause of bias in CMIP5 models, we instead imposed the spatially varying climatological annual mean $r$ from, first, ECMWF and, second, the CMIP5 multimodel mean. $f_{1}^{\prime}$ comes into the GHG forcing due to rising $\mathrm{CO}_{2}$. This is the change in downward longwave radiation at the surface due to increased absorption of upward longwave radiation by increased $\mathrm{CO}_{2}$ and its re-emission down to the surface. As $f_{1}$ decreases, longwave cooling of the surface decreases. Hence, rising $\mathrm{CO}_{2}$ causes a decrease in $f_{1}$. Doubling of $\mathrm{CO}_{2}$ causes an increase in downward longwave radiation of $\sim 3 \mathrm{~W} \mathrm{~m}^{-2}$. Over 1958-2017, the $\mathrm{CO}_{2}$ changed from $\sim 300$ to $\sim 400 \mathrm{ppm}$, which would be about $0.75 \mathrm{~W} \mathrm{~m}^{-2}$. Hence, $f_{1}^{\prime} \approx-0.75 /\left(\varepsilon \sigma \bar{T}_{\mathrm{s}}^{4}\left(1-a C^{2}\right)\right)$, which can be evaluated for a tropical Pacific mean $T_{\mathrm{s}}$ of $301 \mathrm{~K}$ and $C$ of 0.6 .

For the atmosphere model, the parameters and constants are as follows: $z_{\mathrm{T}}=15,000 \mathrm{~m}, \theta_{00}=300 \mathrm{~K}, \varepsilon_{u}=1 / .75 \mathrm{~d}, \varepsilon_{v}=\frac{1}{2} \varepsilon_{u}, K=1 / 10 \mathrm{~d}$ $; N^{2}=3 \times 10^{-4} \mathrm{~s}^{-2}, c_{\mathrm{pa}}=1,000 \mathrm{~J} \mathrm{~kg}^{-1} \mathrm{~K}^{-1}, L=2.5 \times 10^{6} \mathrm{~J} \mathrm{~kg}^{-1}$; and $\bar{\rho}=0.3 \mathrm{~kg} \mathrm{~m}^{-3}, \rho_{00}=1.225 \mathrm{~kg} \mathrm{~m}^{-3}, H_{\mathrm{q}}=1,800 \mathrm{~m}$. For coupling, the drag coefficient, $c_{\mathrm{D}}$-used to convert modelled winds into stresses to force the ocean component-is $2.25 \times 10^{-3}$, which is about $50 \%$ larger than typical values, but was found necessary for a coupled response with approximately the observed amplitude.

\section{Data availability}

All data used or analysed in this study, or generated by other groups and organizations, are publicly available at the links provided in the Methods. Data from our model simulations are available at http://kage.ldeo.columbia.edu:81/ SOURCES/.LDEO/.ClimateGroup/.PROJECTS/.PublicationsData/.Seager_etal_ NCC-2019/.

\section{Code availability}

The Python code for the atmosphere model is in a Juypter Notebook and is available on request. The ocean model code is built on legacy Fortran 90 and C code, and a TAR file of the source code can be made available on request.

\section{References}

27. Davey, M. K. \& Gill, A. E. Experiments on tropical circulation with a simple moist model. Q. J. R. Meteor. Soc. 113, 1237-1269 (1987).

28. Zebiak, S. E. Atmospheric convergence feedback in a simple model for El Niño. Mon. Weather Rev. 114, 1263-1271 (1986).

29. Seager, R. A simple model of the climatology and variability of the low-level wind field in the tropics. J. Clim. 4, 164-179 (1991).

30. Seager, R., Zebiak, S. E. \& Cane, M. B. A model of the tropical Pacific sea surface temperature climatology. J. Geophys. Res. 93, 1265-1280 (1988).

31. Israeli, M., Naik, N. A. \& Cane, M. A. An unconditionally stable scheme for the shallow water equations. Mon. Weather Rev. 128, 810-823 (2000).

32. Ishii, M. \& Kimoto, M. Reevaluation of historical ocean heat content variations with time-varying XBT and MBT depth bias corrections. J. Oceanogr. 65, 287-299 (2009).

33. Carton, J. A. \& Giese, B. S. A reanalysis of ocean climate using Simple Ocean Data Assimilation (SODA). Mon. Weather Rev. 136, 2999-3017 (2008).

34. Good, S. A., Martin, M. J. \& Rayner, N. A. EN4: quality controlled ocean temperature and salinity profiles and monthly objective analyses with uncertainty estimates. J. Geophys. Res. Oceans 118, 6704-6716 (2013). 
35. Kobayashi, S. et al. The JRA-55 reanalysis: general specifications and basic characteristics. J. Meteor. Soc. Jpn 93, 5-48 (2015).

36. Compo, G. P. et al. The twentieth century reanalysis project. Q. J. R. Meteor. Soc. 137, 1-28 (2010).

37. Taylor, K. E., Stouffer, R. J. \& Meehl, G. A. An overview of CMIP5 and the experimental design. Bull. Am. Meteor. Soc. 93, 485-498 (2012).

38. Kay, J. E. et al. The Community Earth System Model (CESM) Large Ensemble Project: a community resource for studying climate change in the presence of internal climate variability. Bull. Am. Meteor. Soc. 96, 1333-1349 (2015).
39. Rayner, N. A. et al. Global analyses of sea surface temperature, sea ice, and night marine air temperature since the late nineteenth century. J. Geophys. Res. 108, 4407 (2003).

40. Kistler, R. et al. The NCEP-NCAR 50-year reanalysis: monthly means CD-ROM and documentation. Bull. Am. Meteor. Soc. 82, 247-268 (2001).

41. Huang, B. et al. Extended Reconstructed Sea Surface Temperature, version 4 (ERSSTv5): upgrades, validations and intercomparisons. J. Clim. $\mathbf{3 0}$, 8179-8205 (2017). 